\title{
ESTRUCTURA DE PROPIEDAD Y POSESIÓN DE LA TIERRA EN LA COMUNIDAD CAMPESINA DE PALCA HUANCAVELICA
}

\section{PROPERTY STRUCTURE AND POSSESSIÓN OF THE LAND OF PALCA'S COMMUNITY FARM IN HUANCAVELICA}

\author{
Gualberto Poma Castellanos'
}

\begin{abstract}
RESUMEN
Estudiar el régimen de propiedad y posesión de la tierra en la Comunidad Campesina de Palca, Huancavelica implica entender las relaciones de producción y el meollo de estas la constituyen: la propiedad o posesión de la tierra y la existencia de sectores sociales y la lucha entre éstas. Las comunidades campesinas, como forma de organización socio-económica del campesinado, expresa la relación dialéctica entre lo comunal y lo familiar. Siendo las modalidades de obtención de tierras en la Comunidad Campesina de Palca por parte de las familias campesinas por posesión o usufructo por compra-venta, arrendamiento y al partir, estos dos últimos temporalmente.
\end{abstract}

Palabras clave: Estructura de propiedad -

Comunidad Campesina - propiedad comunal.

\begin{abstract}
To study the Property regime and possession of the land in the Rural Community of Palca - Huancavelica implies to understand the production relationships and the kernel of these it constitute: the property or possession of the land and the existence of social sectors and the fight among them. The rural communities, like socio-economic organization form of the peasant, expresses the dialectical relationship between the communal thing and the family thing. Being the modalities of lands obtaining in the Rural Community of Palca on the part of the rural families for possession or usufructed for purchase-sale, lease and when leaving, these two last temporarily.
\end{abstract}

Key words: Property structure, community land association, community property. 


\section{INTRODUCCIÓN}

El estudio de la estructura de propiedad y posesión de la tierra en la Comunidad Campesina de Palca, Huancavelica, constituye una forma peculiar de ver la organización social del sector campesinado dentro del conjunto de la sociedad global.

Esta comunidad está definida por tres rasgos: La propiedad colectiva de un espacio rural usufructuado por los mismos de manera individual y colectiva, una forma de organización social basada especialmente en la reciprocidad (1), y por el mantenimiento de una democracia y patrón cultural singular que recoge elementos del mundo andino.

En esta comunidad cada familia tiene una o más parcelas dentro de la Comunidad y pueden cambiar los cultivos o el uso de la tierra según su criterio, ellos pueden vender la tierra a otro miembro de la comunidad. La propiedad por una parte es comunal y por otra parte de las familias es privada, esta última es decidida de manera individual y legal sobre la tierra. Finalmente las modalidades de obtención de tierras en la Comunidad Campesina de Palca de las familias campesinas se dan por posesión o usufructo, por compra-venta, arrendamiento y al partir.

\section{MATERIAL Y MÉTODOS}

Se utilizó el método de investigación del análisis y síntesis. Las dimensiones de análisis constituyeron la propiedad y posesión de la tierra y, la comunidad campesina en descomposición; Las unidades de análisis fueron las familias campesinas y las autoridades comunales por anexos; mientras la contrastación de las hipótesis planteadas se realizó a través del diseño descriptivo simple no experimental; las técnicas de recolección de datos utilizados han sido la observación no participativa y participativa, la recopilación documental y la entrevista. Los instrumentos fueron, la guía de observación, las fichas de trascripción y la guía de entrevista.

\section{RESULTADOS}

Propiedad y Posesión de la Tierra
En cuanto se refiere a la forma de propiedad de la tierra, en Palca lo dominante fue y sigue siendo la propiedad colectiva sobre sus tierras, aguas, pastos y bosques, derivado en un derecho ancestral que se remonta al siglo XIX, en ese sentido la Comunidad de Palca, en la actualidad, según la memoria descriptiva de 1997, es propietaria de 7671,25 hectáreas de territorio, cuya superficie, de acuerdo al uso o naturaleza de la tierra estaba dividida del siguiente modo:

Como se puede observar el total de estas tierras es

Tabla 1. Clasificación de las tierras de la Comunidad Campesina de Palca.

\begin{tabular}{|c|c|c|c|}
\hline Simbología & Tipo de tierras & Área (hectá reas) & $\%$ \\
\hline TC & Terrenos de cultivo & 4602,75 & 60 \\
\hline PN & Pastos naturales & 1534,25 & 20 \\
\hline CA & Cobertura arbórea & 767,12 & 10 \\
\hline UNA & Uso no agrícola & 383,56 & 5 \\
\hline TD & Terreno desnudo & 375,89 & 4,9 \\
\hline MA & Masa de agua & 7,67 & 0,1 \\
\hline Total & & 7671,25 & 100 \\
\hline
\end{tabular}

Fuenter Mem oria descriptiva de la Com unidad Cam pesina de $\mathrm{P}$ alca, Huancavelica, 1997.

de propiedad comunal; el $60 \%$ son útiles para la agricultura en los diferentes pisos ecológicos donde la producción es diversa, el $20 \%$ de estas tierras son pastos naturales, donde las familias comuneras crían ganado vacuno, ovino, camélidos sudamericanos, caballar, asnal y animales menores, mientras el $10 \%$ sirve como cobertura arbórea, como montes y bosques para leña y otros usos, el $5 \%$ son de uso no agrícola, el $4,9 \%$ son terrenos desnudos que comprende las quebradas y el $0,1 \%$ son ríos y lagos.

En un país donde existe la exclusión de las mayorías y el monopolio de las minorías (2), la comunidad de Palca detenta el derecho de propiedad jurídicamente reconocida, por que las familias comuneras están asociadas y organizadas dentro de un territorio comunal (3), sobre la totalidad de las tierras sin embargo, las tierras de cultivo, tanto de secano así como de riego, están poseídas o usufructuadas por las familias campesinas de manera individual las parcelas. En efecto, las tierras agrícolas de la comunidad, están divididas en parcelas o chacras individuales, produciendo íntegramente sus parcelas para ellos propios, existen zonas o "laymis" que se cultivan rotativamente de acuerdo a los ciclos de descanso de las tierras. El ciclo de rotación varía entre dos a cinco años, dependiendo de la 
disponibilidad de las tierras para sembrar, porque en algunos casos no pueden darse el lujo de dejar descansar una tierra necesaria tanto tiempo. Este descanso de la tierra, considerado "obligatorio" o "necesario en la sierra es consecuencia directa del bajo nivel de desarrollo de las fuerzas productivas. La falta de fertilizantes y técnicas apropiadas de trabajo, etc. obligan al descanso.

La propiedad y tenencia en común del espacio físico y la forma específica como es utilizado y administrado constituye uno de los rasgos sustantivos que definen a la Comunidad Campesina de Palca. Los comuneros se identifican con dicho territorio, poseído generalmente desde tiempos inmemoriales. Por lo que recuperó muchas tierras que les perteneció desde sus ancestros (5).

El espacio físico de la comunidad como dice Matos Mar, está dividida en tres zonas: 1. (el núcleo urbano y sus anexos); 2. (las áreas de cultivo aledañas) y 3. (las zonas de pastos). El espacio urbano, está ubicado en el centro del territorio comunal. Este centro de la población es parte de la antigua reducción, actualmente sobre la base de esta comunidad se creó el distrito, los anexos tienen similar crecimiento poblacional por ende tienen la misma configuración de asentamiento de la capital, distribuidos en la periferia del territorio comunal en función de las actividades productivas, agrícolas o ganaderas. Dado que su vinculación con el núcleo central es de dependencia, ganando cierta importancia, tendiendo a segmentarse de la comunidad madre y a constituirse en otra independiente. Pero conviene aclarar que no toda la tierra agrícola comunal ha sido privatizada. Subsisten en todos los anexos, zonas reservadas para las comunidades, escuelas y otras instituciones, en tanto que se mantiene el carácter comunal de la propiedad como su trabajo comunal.

Los pastos naturales en la capital de la comunidad y los anexos constituyen la mayor extensión del dominio comunal. Generalmente se encuentran en punas o lomas, en las que el aprovechamiento del suelo es casi exclusivo para la ganadería de auquénidos, vacunos, ovinos, caballar, asnal y caprino. Entre el Centro Poblado y la puna generalmente existen una zona intermedia en las que se hallan las "estancias" o "paraderos" de ganadería extensiva (4) y, sobre todo, moyas o extensiones agrícolas dedicados mayormente al cultivo de la papa.

En la gran área de pastos, en la que se incluyen las moyas, la propiedad y el usufructo mantiene un carácter comunal. Los comuneros disponen de ella casi sin restricciones, únicamente con la aceptación comunal. Mientras que en las estancias, la tenencia es dual, ya que se dan formas de privatización entre los comuneros más poderosos; pero en última instancia la tierra pertenece a la comunidad (7).

\section{DISCUSIÓN}

\section{Régimen y uso de la tierra en la Comunidad de Palca}

Está totalmente prohibido el acaparamiento de tierras comunales dentro de la comunidad, la Directiva comunal, lleva un padrón comunal (8), como el padrón o registro de uso de las tierras incluyendo las que contengan los pastos naturales. Entonces, las parcelas familiares no superarán a las fijadas por la Asamblea General.

Los recursos forestales existentes en las tierras comunales, es explotado exclusivamente por la comunidad, por ninguna causa o motivo se concede a terceros y/o comuneros para su explotación.

La Comunidad recupera la posesión de las parcelas abandonadas o no explotadas en forma directa por los comuneros (9), así como las que excedan a la extensión fijada por la Asamblea General.

En las tierras de pastos naturales, la Asamblea determina la cantidad máxima de ganado por familia para el pastoreo, así como la destinada al establecimiento de unidades de producción comunal.

Está totalmente prohibido pastar ganado de cualquier especie que no sea de su propiedad, quién no acate esta disposición es sancionado con la reducción tanto de su parcela así como del número de cabezas de ganado de su propiedad.

\section{Modalidades de obtención de las tierras por posesión o usufructo}

Las tierras comunales, que en alguna oportunidad fue parcelada y entregada en usufructo temporalmente o de por vida a una familia campesina, con el transcurrir de los años, al no producirse los repartos periódicos de tierras, se convirtieron automáticamente en posesión privada de una familia comunera.

Aquí significa la relativa apropiación individual de las parcelas adjudicadas ya son absolutas para la familia, la posesión prácticamente se ha convertido en posesión para toda la vida, por ende puede vender, arrendar y puede dar a partir, lo cierto no tienen documentos que ampara su propiedad. En 
caso de las "estancias" o "paraderos", es de manera similar con las tierras agrícolas, pero una parte de la tierra, principalmente los pastizales, es propiedad comunal, mientras que los terrenos de cultivo son de propiedad privada, es decir, los dueños de las parcelas pueden disponer de éstas libremente aunque están prohibidas la venta a personas ajenas a la comunidad.

"Anteriormente cuando alguien se casaba, la comunidad inmediatamente integraba a la comunidad sin que nosotros pidamos y también inmediatamente la comunidad entregaba un pedazo de tierra, que ahora ya no se da, porque hay pocas tierras comunales", "por el aumento de la población, las chacras que sembramos es lo que nuestros padres nos han dejado en herencia, así nosotros también repartimos a nuestros hijos, por eso nuestras chacras ya son muy pedacitos" (Samuel Chávez, comunero del Anexo de Manchaylla).

\section{Compra - Venta}

Según testimonios en la actualidad, es un procedimiento generalizado la adquisición de tierras agrícolas, los corrales de pastizales y las casas estancias, esto mediante escritura de compra y venta celebrados en el Juez de Paz del pueblo, Presidente de la comunidad, en los anexos en el Teniente Gobernador o en todo caso un simple documento de compra y venta entre las dos partes.

Estos mecanismos de acceder a la parcela de tierras por parte de las familias campesinas en la comunidad de Palca, indican que se están desarrollando un avanzado proceso de privatización de las tierras agrícolas, como también de la ganadería privatizada, en beneficio de las familias campesinas, y a su vez el desarrollo de un mercado de tierras, lo que implica en la realidad que la producción comunal es sólo una formalidad jurídica.

"Cuando falleció mis padres las tierras que me dejó vendí a mis primos que siguen radicando en el pueblo, pero el precio es muy barato, hicimos un documentito sólo entre nosotros porque somos familia, con otra persona que no es familia para mayor garantía hicimos el documento en el Teniente Gobernador" (Zenón Felipe, inmigrante a Lima. Anexo de Ornobamba).

\section{El Arrendamiento}

Esta otra modalidad de acceso a la tenencia de la tierra cultivable básicamente es cuando algunas familias campesinas en la capital como en los anexos de la comunidad arriendan tierras agrícolas, por uno, dos o más años, según el acuerdo con el propietario de las parcelas que generalmente están fuera de la comunidad.

El arrendamiento no sólo se da con las tierras agrícolas sino también con los corrales pastizales.

"Yo arriendo mis chacras a familiares o a otras personas, el pago que me hacen son de acuerdo al tamaño del terreno, no hacemos algún documento sólo aquí vale la palabra" (Julia Anccasi, inmigrante a Huancayo. Anexo de Ñuñungayocc).

\section{La Aparcería}

Esto es otra forma de acceder a la tierra y al ganado, el propietario de la tierra que él no trabaja la entrega al campesino aparcero a cambio de una renta en productos, equivalente a la mitad de la cosecha. Aquí, el aparcero pone la semilla, y se encarga del cuidado total.

En la cosecha el dueño de la tierra o algún familiar que lo representa, va a la chacra y juntamente con el campesino aparcero se reparte lo producido en partes iguales. Esta repartición adopta formas distintas, puede hacerse por sacos de papas, por líneas de surcos, o un surco para uno y el siguiente para el otro. El dueño de la tierra ofrece a veces al campesino aparcero un "miskipa".

En caso la aparcería en la ganadería, este caso sobre todo en los anexos alto andinas, el propietario del ganado cualquier especie sea entrega al aparcero por un periodo de un año, durante este año el dueño debe asistir al aparcero con un porcentaje de alimentos para el y para el perro, después de un año se reparten no todo el ganado, sino sólo las crías. Testimonio de Luis Rojas Poma del Anexo de Ñuñungayooc, propietario: "también tenemos ganado "al partir"; es decir yo entrego una vaca a un "partidario". Este debe alimentar durante dos años y nos repartimos las crías, la primera cría para el partidario, la segunda para nosotros".

Esta forma de acceder a la tierra o a la ganadería es cotidiana en el área de la comunidad, la relación de explotación entre propietario y campesino aparcero se da de hecho en la medida en que hay de parte del propietario una apropiación de parte del trabajo del aparcero. Más exactamente, de la mitad del trabajo que supone la parcela, por el solo hecho de tener la propiedad jurídica de la tierra y ganado. 


\section{REFERENCIAS BIBLIOGRAFICAS}

1. Fuenzalida F. Estructura de la Comunidad de Indígenas tradicionales. En matos Mar. Hacienda, comunidad y campesinados en el Perú. Lima;1976.

2. Burga M; Flores G. Apogeo y crisis de la República Aristocrática. Lima: Ediciones Rikchay Perú; 1981.

3. Gonzales de Olarte E. Economía de la Comunidad Campesina. Lima: IEP; 1984.

4. Matos J. Hacienda, comunidad y campesinado. Lima: IEP; 1985.
5. Espinoza G; Malpica C. El Problema de la Tierra: Presencia y Proyección de los 7 ensayos. Lima: Editorial Amauta; 1978.

6. Figueroa A. La Economía Campesina en la Sierra del Perú. PUCP. Lima: Fondo Editorial; 1983.

7. Plaza O. La economía campesina. Lima: DESCO; 1991.

8. Padrón General de la Comunidad campesina de Palca 2002-2004. Palca; 2002.

9. Estatuto de la Comunidad Campesina de Palca; 1995

E-mail: gu_alberto_01@ hotmail.com 